\title{
Highlights from the 79th Scientific Sessions of the American Diabetes Association
}

\author{
Dr Caroline Day reviews the \\ meeting in San Francisco, \\ 7-11 June 2019
}

\section{Introduction}

This year more than 15,000 people from 115 countries converged on the Moscone Center in downtown San Francisco, California for the 79th scientific sessions of the American Diabetes Association (ADA). As always, it is an understatement to say that delegates are only involved in diabetes-related activities from dawn to dusk (check out the programme). ${ }^{1}$ The holder of the record for the fastest 5K@ADA run (1 mile/ 4.45 minutes in San Diego, 2011), Martin Parkhøi, was this year's winner with a chip time of 16.12 minutes averaging 1 mile in 5.14 minutes - an even more impressive feat considering he was in the 45-49 year age group.

A networking reception on the first evening permitted a tasting of hors d'oeuvres prepared using recipes from the ADA's award winning cook books - relatively healthy but not calorie free (the ADA consensus report on nutrition was launched the next morning). ${ }^{2} \mathrm{At}$ the same time, the Women's Interprofessional Network of the ADA was also holding a reception nearby at which the first Lois Jovanovic Transformative Woman in Diabetes Award (in collaboration with Sansum Diabetes Research Institute) was presented to $\mathrm{Dr}$ Elizabeth R Seaquist. This award - in honour of Dr Lois Jovanovic, scientist and physician, who died in September 2018 - recognises a woman who has made a significant impact in diabetes care, research, education or public health. Continuing to recognise the contribution of women, but beyond the world of diabetes, followers of the FIFA Women's World Cup were able to keep abreast of the action in a dedicated viewing lounge (an armchair athlete activity).

\section{e-only}

The 2019 meeting saw the demise of the Abstract book and hard copy of the programme. To navigate the meeting it was necessary to download the meeting app (ADA Events Mobile App: via Google Play, the App Store or visit m.core-apps.com/tristar_ada_events). The abstracts are available via the App and the ADA journal webpage. The virtual Abstract book also contains the late breaking abstracts. ${ }^{3}$ Booth 909 in the exhibition hall

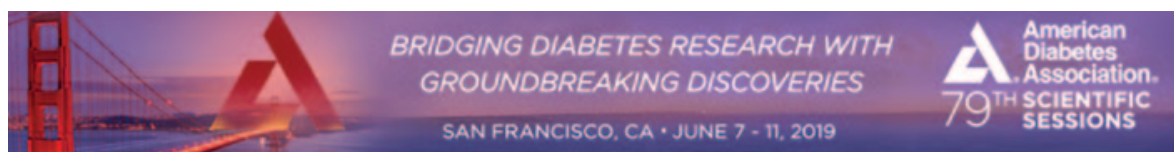

Table 1 Awards

\section{National Scientific \& Health Care Achievement Awards and Lectures Recipient}

Banting Medal for Scientific Achievement Award

Stephen O'Rahilly, UK Lecture: Treasure Your Expectations - Studying Human Extreme Phenotypes to Illuminate Metabolic Health and Disease (9 June)

Kelly West Award for Outstanding Achievement in Epidemiology Lecture: Improving Outcomes -Translating Epidemiology to

Clinical Trials (9 June)

Outstanding Scientific Achievement Award

Lecture: Obesity and the Biology of Weight Regulation (10 June)

Outstanding Educator in Diabetes Award

Lecture: The Most Important Thing We Give to People is Hope -

Overcoming Stigma in Diabetes and Obesity (8 June)

Outstanding Achievement in Clinical Diabetes Research Award

Outstanding Physician Clinician in Diabetes Award

Elizabeth Mayer-Davis, USA

Sadaf Farooqi, UK

Virginia Valentine, USA

Albert Renold Award

John B Buse, USA

David C Klonoff, USA

Harold Rifkin Award for Distinguished International Service in the Cause of Diabetes

Rudolf L Leibel, USA

Juliana CN Chan, Hong Kong

\section{Professional Interest Group Award Lectures}

\section{Recipient}

Edwin Bierman Award (Complications)

Lecture: Linking Kidney and Cardiovascular Complications - Impact on Prognosis and Treatment (10 June)

Norbert Freinkel Award (Pregnancy)

Lecture: Translating Research on Diabetes and Obesity in Pregnancy into Prevention (9 June)

Roger Pecorara Award (Foot Care)

Lecture: Artificial Intelligence for Predicting Diabetes-Related Foot Ulcer Outcomes (8 June)

Richard R Rubin Award (Behavioural Medicine \& Psychology) Lecture: \#DiabetesPsychologyMatters (8 June)

Frank J Snoek

The Netherlands

was the place to go to get a USB stick with Pdfs of the abstracts and a webkey to view full-scale e-posters at any time, otherwise the e-posters could be seen on computers in the poster hall. ${ }^{4}$ The e-theme continued via a chip in your name badge as the ADA piloted Radio-Frequency Identification technology to track individual movements in the Poster and Exhibit halls and the Stop Diabetes Store in order to enable better planning of upcoming events. (In future, beware of loitering round the stand with the best coffee or even a 'nonmeeting' assignation - who knows when a hacker will expose the clandestine behaviour of 'lazy' delegates). For the complete e-experience (electronic, economic, ecological), why not access webcasts of the sessions and industry symposia from home? ${ }^{5}$

\section{Highlights}

As always, the award lectures are high points of the meeting and 2019 was no exception, with the UK carrying home the Banting Medal and Outstanding Scientific Achievement Award (Table 1).

The cardiovascular outcome trials (CVOTs) 
have been promoted as the 'must see' presentations at recent diabetes meetings, but at this ADA there was competition from other large studies.

\section{Prevention, remission, progression}

Prevention studies such as the D2d (MiniSymposium 7 June) showed that supplementation with vitamin D3 (4,000 IU/day) for a median of 2.5 years in adults with prediabetes $(n=2,423)$ did not significantly reduce progression to type 2 diabetes mellitus (T2DM) compared with controls (9.36 vs 10.66 per 1,000 patient-years). ${ }^{6}$ The multinational PREVIEW study (Symposium 8 June) compared four diet and weight management programmes in people with pre-diabetes $(n=2,223)$. All participants commenced the 3year study on a 2-month total meal replacement regimen of $800 \mathrm{kcal} /$ day, resulting in 2,202 of them losing $\geq 8 \%$ of their body weight. At randomisation, 35\% of participants no longer had pre-diabetes, but this had dropped to $18.5 \%$ by study end. In those who had initial weight loss the rates of delay in progression to T2DM were comparable across the four study programmes; however, $<50 \%$ of participants completed the study (evidence that cutting calories is tough?). In 1986 the Da Qing diabetes prevention study randomised people $(n=576)$ with impaired glucose tolerance (IGT) to control or lifestyle interventions (diet/exercise/diet plus exercise). After 6 years, 32\% had achieved normal glycaemic control whilst $46 \%$ had progressed to T2DM. The 30-year follow-up showed that reverting to normoglycaemia and delaying progression from IGT to T2DM reduced the incidence of adverse microvascular and macrovascular outcomes. ${ }^{7}$ At the 2-year follow-up of a sub-group ( $n=40)$ of T2DM patients who had initially achieved remission after diet-induced weight loss in the DiRECT study, 20 remained in remission, 13 had gained weight and relapsed and 7 were lost to follow-up. Those who remained in remission showed improved insulin secretory responses and support the thesis that durable remission of T2DM is possible if weight regain is minimised. ${ }^{8}$

The RISE study (Symposium 9 June) highlighted the progressive nature of T2DM, showing that improvements in beta cell function during 12 months of treatment did not persist 3 months after withdrawal of pharmaceutical therapy in adults $(n=267)$ with IGT or newly diagnosed ( $<1$ year) treatment-naïve T2DM. ${ }^{9}$ A similar protocol of 12 months of treatment followed by 3 months washout compared responses in adults $(n=132)$ and obese youth ( $n=91$, age $<20$ years) with IGT or newly diagnosed ( $<1$ year) treatment-naïve T2DM. Whilst the adults showed improvements in beta cell function during treatment, beta cell function in youth deteriorated during treatment as well as following treatment withdrawal, suggesting T2DM in youth has a more aggressive progressive pathology. ${ }^{10}$

The TODAY study (Symposium 8 June) ran from 2004 to 2011 ( $n=699$, age 14 years, 6 months since diagnosis) and continuing treatment and follow-up occurred until 2014 in TODAY phase 1 (T2P1, $n=572$ ). The study is continuing as an observation-only follow-up until 2020 as TODAY phase 2 (T2P2, n=517), but medication costs are no longer covered. Throughout the TODAY programme participants have been obese $\left(\mathrm{BMl}>34 \mathrm{~kg} / \mathrm{m}^{2}\right)$ and mean $\mathrm{HbA}_{1 c}$ had increased from $6 \%$ at baseline to $9.3 \%$ in 2014. Diabetes-associated complications occurred after a shorter duration of T2DM in youth than in those with adult-onset diabetes - the cardiovascular event rate $(6.41 / 1,000$ patient-years) was triple that observed in the DCCT: by 12 years $9 \%$ of the cohort required treatment for advanced retinopathy, up to $33 \%$ had evidence of neuropathy and $40 \%$ had albuminuria. There were 306 pregnancies: maternal complications were higher than expected in a T2DM population as were obstetric complications, miscarriage and adverse fetal outcomes such as respiratory distress, macrosomia and cardiac defects.

\section{Outcomes}

The term CVOTs was originally given to phase 4 post-marketing safety studies required by the US FDA. Now, however, it has become a colloquial label ascribed to a broader range of phase 3 and phase 4 trials which investigate the effect of a 'new' drug on major adverse cardiovascular events (MACE) - usually a composite of cardiovascular (CV) death, nonfatal myocardial infarction and non-fatal stroke. Headline results from CAROLINA, CARMELINA, REWIND - including a renal analysis - and PIONEER 6 (see Table 2) and subgroup analyses from DECLARE (Symposium 9 June) and the renal outcomes trial CREDENCE (Symposium 11 June) were reported in symposia at this meeting. ${ }^{11-17}$

CAROLINA debunked the promoted view that second-generation sulfonylureas increase $\mathrm{CV}$ risk. Treatment with glimepiride was noninferior to treatment with linagliptin with regard to MACE and offered a similar risk of CV death. Despite similar glycaemic control, more patients experienced any hypoglycaemia on glimepiride (37.7\%) than on linagliptin (10.6\%). ${ }^{11}$ The 'new drugs' in CARMELINA, PIONEER 6 and REWIND were all non-inferior to usual care. ${ }^{12-14}$

CREDENCE (Symposium 11 June) was a study in patients $(n=4,401)$ with established T2DM (mean 15.8 years) and chronic kidney disease. Treatment with canagliflozin (100 $\mathrm{mg}$ ) for a median of 2.5 years was terminated early (July 2018) due to achieving pre-specified efficacy criteria (eg, cutting risk of renal failure and death by $30 \%$ ). Canagliflozin reduced the risk of MACE by $32 \%$ and $15 \%$; CV death or hospitalisation for heart failure by $26 \%$ and $34 \%$; and CV death by $25 \%$ and $21 \%$, respectively, in patients without (49.6\%) and with (50.4\%) a history of CVD. ${ }^{16}$ In DECLARE (Symposium 9 June), 17,160 patients had established T2DM (median 11 years) but fewer than half (40.6\%) had established CVD and only $7.4 \%$ had an estimated glomerular filtration rate (eGFR) $<60 \mathrm{~mL}$ $\mathrm{min} / 1.73 \mathrm{~m}^{2}$. Treatment with dapagliflozin (10 mg) for a median of 4.2 years improved the composite cardiorenal outcome, the composite renal-specific outcome and retarded the decline of eGFR to $<60 \mathrm{~mL} / \mathrm{min} / 1.73 \mathrm{~m}^{2}$ compared with placebo (all $p<0.0001$ ) and reduced end stage renal disease or renal death $(p<0.01) .{ }^{15}$ In CARMELINA, in which

Table 2 Latest Cardiovascular Outcome Trials (CVOTs)

\begin{tabular}{|c|c|c|c|}
\hline \multirow[t]{2}{*}{$\begin{array}{l}\text { Trial } \\
\text { Investigational drug (Symposium date) }\end{array}$} & $\begin{array}{l}\text { Trial start (Patients) } \\
\text { Followed }\end{array}$ & $\begin{array}{l}3 \text { pt MACE } \\
\text { vs usual care* }\end{array}$ & CV death \\
\hline & & \multicolumn{2}{|c|}{ HR $(95 \% \mathrm{Cl})$} \\
\hline $\begin{array}{l}\text { CAROLINA }^{+11} \\
\text { Linagliptin (10 June ) }\end{array}$ & $\begin{array}{l}2010(n=6,033) \\
6.3 \text { years }\end{array}$ & $\begin{array}{l}0.98 \\
(0.84 \text { to } 1.14)\end{array}$ & $\begin{array}{l}1.0 \\
(0.81 \text { to } 1.24)\end{array}$ \\
\hline $\begin{array}{l}\text { CARMELINA }^{12} \\
\text { Linagliptin (11 June) }\end{array}$ & $\begin{array}{l}2013(n=6,979) \\
2.2 \text { years }\end{array}$ & $\begin{array}{l}1.02 \\
(0.89 \text { to } 1.17)\end{array}$ & $\begin{array}{l}0.96 \\
(0.81 \text { to } 1.14)\end{array}$ \\
\hline $\begin{array}{l}\text { PIONEER } 6^{14} \\
\text { Semaglutide oral (11 June) }\end{array}$ & $\begin{array}{l}2017(n=3,183) \\
1.3 \text { years }\end{array}$ & $\begin{array}{l}0.79 * \\
(0.57 \text { to } 1.11)\end{array}$ & $\begin{array}{l}0.49 \\
(0.27 \text { to } 0.92)\end{array}$ \\
\hline $\begin{array}{l}\text { REWIND }{ }^{13} \\
\text { Dulaglutide QW (9 June) }\end{array}$ & $\begin{array}{l}2011(n=9,901) \\
5.4 \text { years }\end{array}$ & $\begin{array}{l}0.88^{*} \\
(0.79 \text { to } 0.99)\end{array}$ & $\begin{array}{l}0.91 \\
(0.78 \text { to } 1.06)\end{array}$ \\
\hline
\end{tabular}


Trial acronyms

\begin{tabular}{|c|c|}
\hline CARMELINA & $\begin{array}{l}\text { CARdiovascular and renal Microvascular outcome Study with LINAgliptin in patients } \\
\text { with type } 2 \text { diabetes mellitus at high vascular risk }\end{array}$ \\
\hline CAROLINA & $\begin{array}{l}\text { CARdiovascular Outcome study of LINAgliptin versus glimepiride in patients with } \\
\text { type } 2 \text { diabetes }\end{array}$ \\
\hline CREDENCE & $\begin{array}{l}\text { Canagliflozin and Renal Endpoints in Diabetes with Established Nephropathy Clinical } \\
\text { Evaluation }\end{array}$ \\
\hline $\mathrm{D} 2 \mathrm{~d}$ & The vitamin D and type 2 diabetes study \\
\hline DCCT & Diabetes Control and Complications Trial \\
\hline DECLARE & $\begin{array}{l}\text { Multicenter trial to evaluate the effect of Dapagliflozin on the incidence of } \\
\text { cardiovascular events }\end{array}$ \\
\hline DiRECT & Diabetes REmission Clinical Trial \\
\hline PIONEER 6 & $\begin{array}{l}\text { A trial investigating the cardiovascular safety of oral semaglutide in subjects with type } \\
2 \text { diabetes }\end{array}$ \\
\hline PREVIEW & $\begin{array}{l}\text { PREVention of diabetes through Lifestyle Intervention and population studies in } \\
\text { Europe and around the World }\end{array}$ \\
\hline REWIND & REsearching cardiovascular events with a Weekly INcretin in Diabetes \\
\hline RISE & Restoring Insulin SEcretion \\
\hline TODAY2 & Longitudinal outcomes in youth with type 2 diabetes \\
\hline
\end{tabular}

$74 \%$ of patients had kidney disease, linagliptin ( $5 \mathrm{mg}$ ) did not show any benefits on the secondary composite renal outcome. ${ }^{12}$ In REWIND, nearly one-third (31\%) of patients had established CVD and about $21 \%$ of patients had eGFR $<60 \mathrm{~mL} / \mathrm{min} / 1.73 \mathrm{~m}^{2}$ and $35 \%$ had albuminuria. Treatment with dulaglutide (1.5 mg once weekly) reduced a composite renal outcome by $15 \%(p=0.0004)$ and the incidence of new macroalbuminuria by $23 \%(p<0.0001) .{ }^{17}$

\section{Novelties}

Recycling remains fashionable (reading the 20th century diabetes literature would have saved time and resource), but there was plenty of useful upcycling. Pre-clinical and early clinical data suggest multi-agonist peptides are the new frontier for incretin-based therapy. The dual agonists tirzepatide, cotadutide, a GLP-1/fibroblast growth factor-21 (FGF21) agonist and the triagonist HM14211 appear to exert powerful effects on glucose, weight and markers of fatty liver disease. Which, if any, will make it to the diabetes formulary?

\section{Diary date}

ADA 2020 is moving north to the shores of Lake Michigan. It will be held on 12-16 June at the McCormick Place Convention Center, Chicago in the West Building (furthest from the waterfront). At 2.5 acres, the Center has the largest rooftop garden in the Mid-West as well as the two largest ballrooms in Chicago - on this occasion presumably all activities will be strictly diabetes.

\section{Acknowledgement} thanks go to Dr Mike Gwilt for pointing me towards some of the content described above.

\section{References}

1. American Diabetes Association, 79th Scientific Sessions, 2019. Final Program. https://professional.diabetes.org/sites/professional.diabetes.or g/files/media/79th_scientific_sessions_final_program.pdf

2. Evert $A B$, Dennison M, Gardner CD, et al. Nutrition therapy for adults with diabetes or pre-diabetes: a consensus report. Diabetes Care 2019; 42:731-54. https://doi.org/10.2337/ dci19-0014

3. American Diabetes Association, 79th Scientific Sessions, 2019. Abstracts. Diabetes 2019;68 (Suppl 1). https://diabetes.diabetesjournals.org/ content/68/Supplement_1

4. American Diabetes Association. ePosters. https:// ada.scientificposters.com/epsWelcome. cfm

5. American Diabetes Association. 79th Scientific Sessions Webcasts 2019. https://professional.diabetes.org/webcasts-ss2019

6. Pittas AG, Dawson-Hughes B, Sheehan P, et al and the D2d Research Group. Vitamin D supplementation and prevention of type 2 diabetes. $N$ Engl J Med 2019;381:520-30. https://doi.org/ 10.1056/NEJMoa1900906

7. Zhyhneuskaya SV, Al-Mrabeh A, Barnes AC, et al. Remission of type 2 diabetes for two years is associated with full recovery of beta-cell functional mass in the diabetes remission clinical trial (DiRECT). Diabetes 2019;68(Suppl 1):Abs 66-OR. https://doi.org/10.2337/db19-66-OR

8. Chen $Y$, Zhang $P$, Wang J, et al. Early progression to diabetes or regression to normal glucose tolerance among people with impaired glucose tolerance affects long-term outcomes: thirty-year follow-up of Da Qing Diabetes Prevention Study.
Nobody can be in two places at once, so
Diabetes 2019;68(Suppl 1):Abs 153-OR. https://doi.org/10.2337/db19-153-OR

9. The RISE Consortium. Lack of durable improvements in $\beta$-cell function following withdrawal of pharmacological interventions in adults with impaired glucose tolerance or recently diagnosed type 2 diabetes. Diabetes Care 2019;42:174251. https://doi.org/10.2337/ dc19-0556

10. The RISE Consortium. Effects of treatment of impaired glucose tolerance or recently diagnosed type 2 diabetes with metformin alone or in combination with insulin glargine on $\beta$-cell function: comparison of responses in youth and adults. Diabetes 2019;68:1670-80. https://doi.org/ $10.2337 / \mathrm{db} 19-0299$

11. Rosenstock J, Kahn SE, Johansen OD, et al for the CAROLINA investigators. Effect of linagliptin vs glimepiride on major adverse cardiovascular outcomes in patients with type 2 diabetes: The CAROLINA randomized clinical trial. JAMA 2019;322:1155-66. https://doi.org/ 10.1001/jama.2019.13772

12. Rosenstock J, Perkovic V, Johansen $O E$, et al. Effect of linagliptin vs placebo on major cardiovascular events in adults with type 2 diabetes and high cardiovascular and renal risk: the CARMELINA randomized clinical trial. JAMA 2019;321:69-79. https://doi.org/10.1001/jama. 2018.18269

13. Gerstein HC, Colhoun HM, Dagenais GR, et al. Dulaglutide and cardiovascular outcomes in type 2 diabetes (REWIND): a double-blind, randomised placebo-controlled trial. Lancet 2019; 394:121-30. https://doi.org/10.1016/S01406736(19)31149-3

14. Husain $M$, Birkenfeld $A L$, Donsmark $M$, et al. Oral semaglutide and cardiovascular outcomes in patients with type 2 diabetes. N Engl J Med 2019; 381:841-51. https://doi.org/10.1056/NEJMoa1901118

15. Mosenzon O, Wiviott SD, Cahn A, et al. Effects of dapagliflozin on development and progression of kidney disease in patients with type 2 diabetes: an analysis from the DECLARE-TIMI 58 randomised trial. Lancet Diabetes Endocrinol 2019;7:606-17. https://doi.org/10.1016/S22138587(19)30180-9

16. Perkovic V, Jardine MJ, Neal B, et al. Canagliflozin and renal outcomes in type 2 diabetes and nephropathy. N Engl J Med 2019;380:2295306. https://doi.org/10.1056/ NEJMoa1811744

17. Gerstein HC, Colhoun HM, Dagenais GR, et al Dulaglutide and renal outcomes in type 2 diabetes: an exploratory analysis of the REWIND randomised, placebo-controlled trial. Lancet 2019;394:131-8. https://doi.org/10.1016/S0140 $-6736(19) 31150-X$.

Correspondence: Dr Caroline Day, Visiting Fellow, Diabetes Group, Aston University, Birmingham B4 7ET, UK E-mail: cday@mededuk.com

http://dx.doi.org/10.15277/bjd.2019.232 Br J Diabetes 2019:19:147-149 